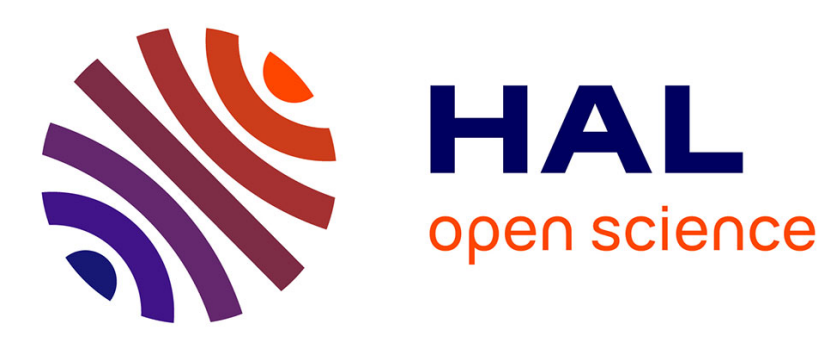

\title{
Improving Video Conferencing Application Quality for a Mobile Terminal through Cognitive Radio
}

\author{
Asma Amraoui, Wassila Baghli, Badr Benmammar
}

\section{To cite this version:}

Asma Amraoui, Wassila Baghli, Badr Benmammar. Improving Video Conferencing Application Quality for a Mobile Terminal through Cognitive Radio. 14th IEEE International Conference on Communication Technology (ICCT 2012), Nov 2012, Chengdu, China. hal-00680897

\section{HAL Id: hal-00680897 \\ https://inria.hal.science/hal-00680897}

Submitted on 20 Mar 2012

HAL is a multi-disciplinary open access archive for the deposit and dissemination of scientific research documents, whether they are published or not. The documents may come from teaching and research institutions in France or abroad, or from public or private research centers.
L'archive ouverte pluridisciplinaire $\mathbf{H A L}$, est destinée au dépôt et à la diffusion de documents scientifiques de niveau recherche, publiés ou non, émanant des établissements d'enseignement et de recherche français ou étrangers, des laboratoires publics ou privés. 


\title{
Improving Video Conferencing Application Quality for a Mobile Terminal through Cognitive Radio
}

\author{
Asma Amraoui, Wassila Baghli, Badr Benmammar \\ LTT Laboratory of Telecommunication Tlemcen \\ UABT TLEMCEN, ALGERIA \\ \{amraoui.asma, wassila.bag, badr.benmammar\}@gmail.com
}

\begin{abstract}
Cognitive radio (CR) is a form of wireless communication in which a transceiver can intelligently detect which communication channels are in use and which are not, and instantly move into vacant channels while avoiding occupied ones. This optimizes the use of available radio-frequency (RF) spectrum while minimizing interference to other users. In this paper, we propose a new approach which uses the CR for improving video conferencing application quality for a cognitive radio mobile terminal (CRMT). We also show through experimentation the interest of our approach.
\end{abstract}

Keywords-Cognitive radio, wireless network, mobility, handover, K-nearest neighbors.

\section{INTRODUCTION}

The Cognitive Radio (CR) was presented officially by Joseph Mitola in 1999, and since, this concept has been very popular with researchers in several fields such as telecommunications, artificial intelligence, and even philosophy. Joseph Mitola has defined the CR as "a radio that employs model-based reasoning to achieve a specified level of competence in radio-related domains" [1].

Applications are often included in its definition because of the compelling and unique applications afforded by CR. Additionally, there are many existing software radio techniques that $\mathrm{CR}$ is expected to enhance. The following are frequently advocated applications of cognitive radio [2]:

- Improving spectrum utilization and efficiency.

- Improving link reliability.

- Advanced network topologies.

- $\quad$ Automated radio resources management.

Most researches on $\mathrm{CR}$ networks have focused on the exploitation of unused spectrum. However, the CR nodes possess the necessary qualities to make a considerable progress in the reliability of wireless networks [2], which has been less explored, so that is why we were interested by improving wireless link reliability.

Connecting mobile users generally consists of a series of fixed and mobile networks. Any consideration of reliability must take into account the end to end network connection. These ideas have been important areas of research in wireline networks [3] and in infrastructure wireless networks [4] [5]. However, the end to end reliability is limited by its weakest components. Traditionally, the wireless link access is seen as the weakest link, and many techniques such as channel coding and diversity have been proposed to the physical layer to improve the quality of radio link [6].

The aim of our paper is to propose a technique to improve wireless link reliability using the CR. For this, it seemed appropriate to choose a CR application and imagine the scenario on which we will apply our approach. Our technique is based on machine learning.

In this paper, we describe the scenarios proposed to improve video conferencing application quality for a CRMT and the results of our experimentation.

\section{SCENARIOS AND PROPOSED SOLUTIONS}

\section{A. Scenario}

The Figure 1 below shows a path followed by a mobile subscriber when it switches to an area where the signal quality drops to an unacceptable level (shown in red) due to a gap in coverage, we assume that the client uses video conferencing over the route.

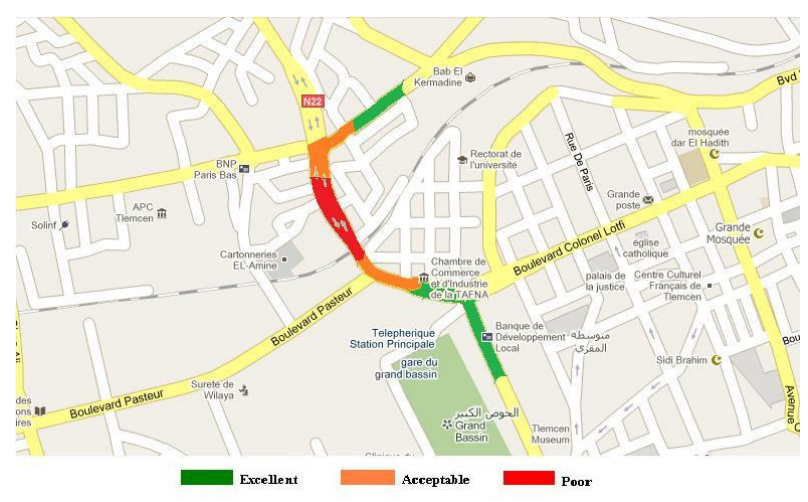

Figure 1 . Signal quality associated to a cognitive radio

\section{B. Proposed Solution}

After several incidents, the CR should be aware of the problem. Then, through some geolocations or the ability to learn the time of the day when this happens, the radio can anticipate the difference in coverage and know the necessary signal to the base station to change characteristics of the signals when the user approaches the deficient coverage. 


\section{Quality of service in video conferencing}

With the emergence of new services such as video conferencing and video streaming, the need to treat the frames one by one and to know how differentiate services becomes primordial.

In the literature, we found that to have a good QoS in video conferencing, it is necessary that:

- Throughput must be $>384 \mathrm{~Kb} / \mathrm{s}$.

- Delay must be $<200 \mathrm{~ms}$.

- $\quad$ Jitter must be $<30 \mathrm{~ms}$.

- $\quad$ Packet loss must be $<1 \%$.

However, as we don't have real data used in the CR and it is the case of the whole community, we had to play the role of the expert to assign the needed data for our simulation.

\section{Application}

As mentioned above, we will use video conferencing in the case of a mobile user who needs to take a path where the signal quality drops to an unacceptable level due to a gap in coverage, giving a very low QoS. This can be remedied by using the CR, but problematic arises: WHEN and WHY to use cognitive radio?

Most research related to the QoS of video conferencing, take into account throughput as pertinent parameter. For this reason, we choose the "Throughput" as a single pertinent parameter for our application. For this, a throughput classification is required, and as we play the role of the expert, we have created our own database following certain rules in order to apply our approach. The database was divided into two parts, the first one for learning and the second one for testing. The value of the throughput will change almost every time it is measured during the day even on the same route, for this reason, our measures have been taken into account for 5 weeks at 3 different intervals of the day (8am - 11am, 11am - 3pm, $3 \mathrm{pm}-5 \mathrm{pm}$ ) excluding weekend.

We proposed to affect throughput on three classes:

- Gold for samples where the throughput is greater than $384 \mathrm{~Kb} / \mathrm{s}$, ensuring $100 \%$ quality satisfaction of the user.

- Silver for samples where the throughput is between $160 \mathrm{~Kb} / \mathrm{s}$ and $384 \mathrm{~Kb} / \mathrm{s}$, of acceptable quality.

- Bronze for samples where the throughput is less than $160 \mathrm{~Kb} / \mathrm{s}$. This means that video conferencing is not satisfactory, and it is the class that interests us because this is when we use the CR.

1) First question "WHEN"?

For the data classification, we used three different algorithms derived from the field of machine learning.

- $\quad$ The k-nearest neighbor's algorithm (K-NN) which is a supervised classification algorithm.

- The multilayer perceptron algorithm (MLP of neural networks).
- The C4.5 algorithm of decision trees.

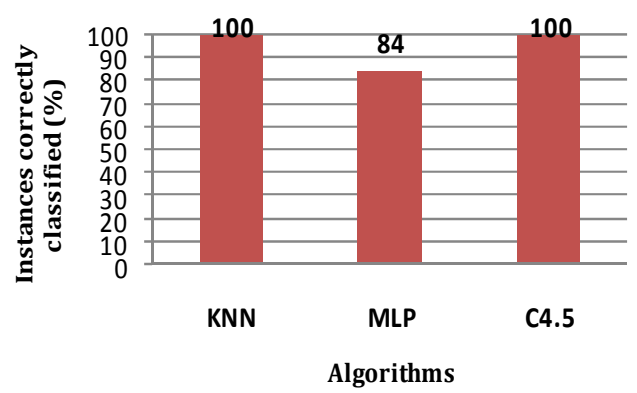

Figure 2. Best scores obtained with the three algorithms

We remark that, the multi layer perceptron has not given satisfactory results compared with the other algorithms; however we did not get $100 \%$, despite the change of parameters such as the number of hidden layers, the number of epochs and the learning rate.

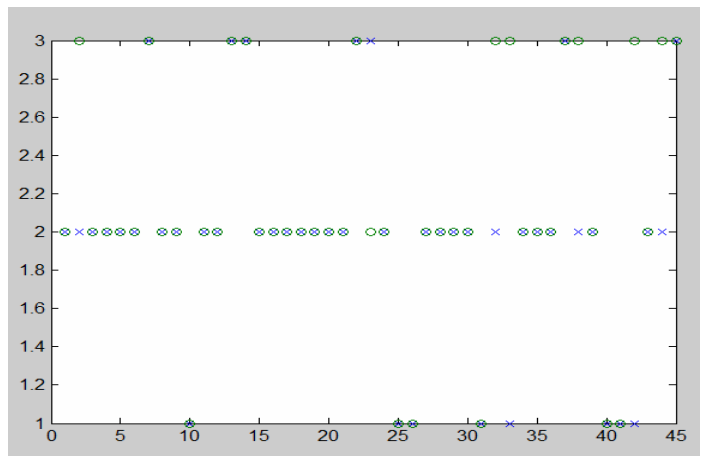

Figure 3. Classification with Matlab

We remark also that the two other algorithms (KNN and C4.5) have given results of $100 \%$, however if we take a look at the generated tree, we see is not exactly what we want because for him the GOLD class starts from a rate of $380 \mathrm{~Kb} / \mathrm{s}$ instead of $384 \mathrm{~Kb} / \mathrm{s}$, this can generate after mistakes with misclassifying some instances. Concerning the K-NN algorithm, it was tested with several values of $K$ on the test database and each time the result was different, but it is satisfactory until the value of $\mathrm{K}=6$. For our approach, we chose this algorithm, as it gave the best results (shown below) in terms of reliability and Clustering.

TABLE I. CLASSIFICATION OBTAINED WITH KNN

\begin{tabular}{|l|l|l|l|l|}
\hline $\begin{array}{c}\text { Values of } \\
\text { K }\end{array}$ & \multicolumn{2}{|c|}{$\begin{array}{c}\text { Instances correctly } \\
\text { classified }\end{array}$} & \multicolumn{2}{c|}{$\begin{array}{c}\text { Misclassified } \\
\text { instances }\end{array}$} \\
\hline $\mathrm{K}=1$ & 20 & $100 \%$ & 0 & $0 \%$ \\
\hline $\mathrm{K}=2$ & 19 & $95 \%$ & 1 & $5 \%$ \\
\hline $\mathrm{K}=3$ & 19 & $95 \%$ & 1 & $5 \%$ \\
\hline $\mathrm{K}=4$ & 18 & $90 \%$ & 2 & $10 \%$ \\
\hline $\mathrm{K}=5$ & 18 & $90 \%$ & 2 & $10 \%$ \\
\hline $\mathrm{K}=6$ & 18 & $90 \%$ & 2 & $10 \%$ \\
\hline
\end{tabular}


For $\mathrm{K}=1$ : All the throughput examples were well posted in their appropriate class.

Whereas, with $\mathrm{K}=2$, one sample was misclassified, we notice that in the graph.

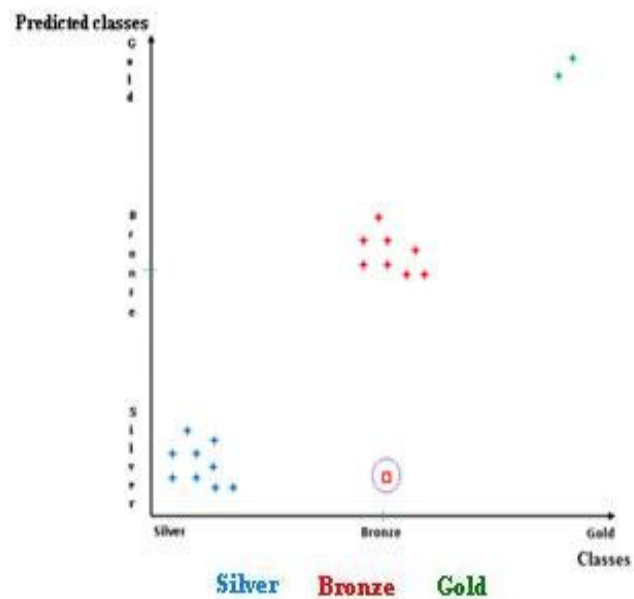

Figure 4: Classification result of $\mathrm{KNN}$ with $\mathrm{K}=2$

Note: items close to the threshold of a class are misclassified. For example, the instance which have a throughput of $159 \mathrm{~Kb} / \mathrm{s}$ was ranked on Silver class instate of the Bronze one, for the other values of $\mathrm{K}$, the result is more divergent.

Report: according to the results of the classification, the cognitive radio will be activated each first day of week from $8 \mathrm{am}$ to $11 \mathrm{am}$ and from $3 \mathrm{pm}$ to $5 \mathrm{pm}$, and every Wednesday from $8 \mathrm{am}$ to $5 \mathrm{pm}$ because in these intervals the throughput belongs to the Bronze class $<160 \mathrm{~Kb} / \mathrm{s}$. So, through this, the question When is answered.

For more general rules, it would be interesting to consider the other QoS video conferencing parameters and classify these data using other methods of artificial intelligence such as fuzzy logic and genetic algorithms.

\section{2) Second question "WHY"?}

Now, We will justify the usefulness of the CR, this by supposing that the spectrum sensing is already done by the receiver of our mobile terminal which is in this case a multimode wireless communication terminal (MWCT), so capable to support multiple access technologies such as GSM, UMTS or WiMAX.

Considering that, the spectrum is not used at $100 \%$, we can represent the frequency bands into two sets: the first contains the occupied bands and the second contains the free ones.

The mobile terminal must switch to an unused frequency band among those available in the free bands set.

For our approach, scenarios were studied to show the usefulness of the $\mathrm{CR}$, this based on the number of free bands and the time of use of each one, we identified three possible scenarios:

- Favorable (best case): the receiver detects a free band and uses it during all the way without any interruption caused by the primary user.

- Unfavorable (worst case): the receiver does not detect any free band (empty set) or it detects some bands but their use interferes with the primary users. In this case the $\mathrm{CR}$ is not used because the secondary user should not disturb the primary users.

- Common ( $\mathrm{N}$ frequency with $\mathrm{N}$ hops): the terminal uses a free band b1, then there is an interruption caused by the primary user, so it switches to another free band $b 2$ (he made a hop). If the primary user of b2 needs his band, the secondary user must switch again, and so on, until the end of the condition when he opts for the CR (before returning to his initial frequency band), he will have done $\mathrm{N}$ hops.

For our application, we have based on the number of hops done by the $\mathrm{CR}$ during all the way of the secondary user. In each of the scenarios mentioned above we calculated the time of interruption which is the required time for the terminal to access a free band and use it.

The time of interruption will be defined as follows: T.interruption $=(\mathrm{T}$.sensing $+\mathrm{T}$. establishment $) \mathrm{x}$ number of hops.

The sensing time is the required time to detect a free band, it is negligible compared to the time of establishment, it is even included in the time of establishment for some algorithms which treat the diagonal handover (switching between wireless networks which uses the subjacent technologies such as the standard IEEE 802) or the vertical handover (switching from one access technology to another).

In the literature, we found that the time of establishment necessary to exploit a free frequency band of another technology is 5 seconds on average [7] and [8].

T.sensing $<<$ T.establishment, which gives us:

T.interruption $=\mathrm{T}$. establishment $\mathrm{x}$ number of hops.

We call time of rupture: the necessary time to return to the initial frequency band. So, it is the sum of the time of interruption and the time of use of each band, knowing that, the time of use can differ from a band to another according to the primary user.

\section{T.rupture $=$ T.interruption + T.use}

\section{3) Experimentation results}

To support our proposal and to better understand, we compared the QoS with and without cognitive radio (case without $\mathrm{CR}$ means that our terminal has only one access technology and works on the same frequency band).

The graphs below illustrate this comparison. For being readable, we supposed that the maximum time of rupture is 5 min and that the free band set contains 7 bands. 


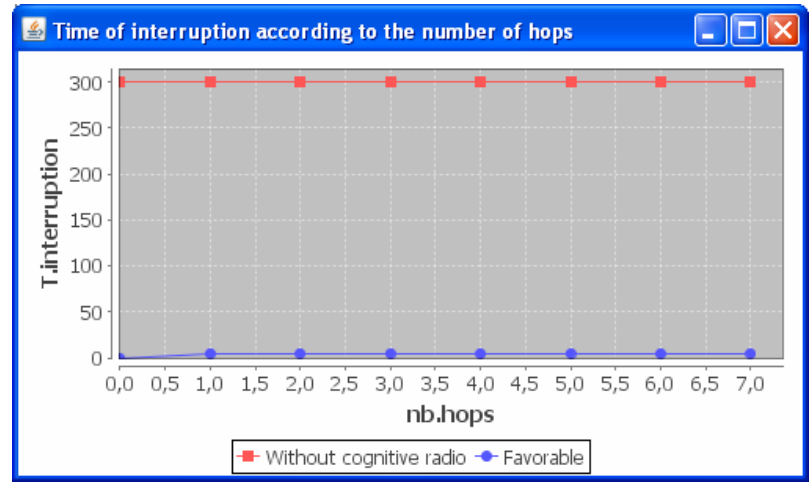

Figure 5. Comparison between the favorable scenario and the case without cognitive radio

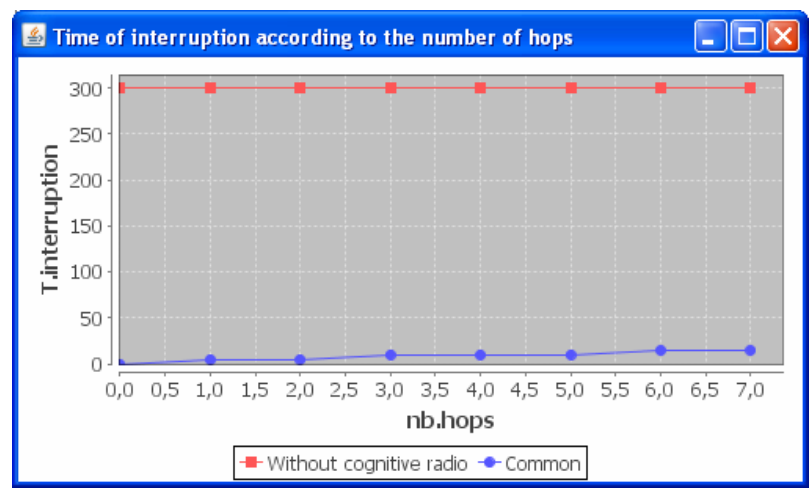

Figure 6. Comparison between the common scenario and the case without cognitive radio

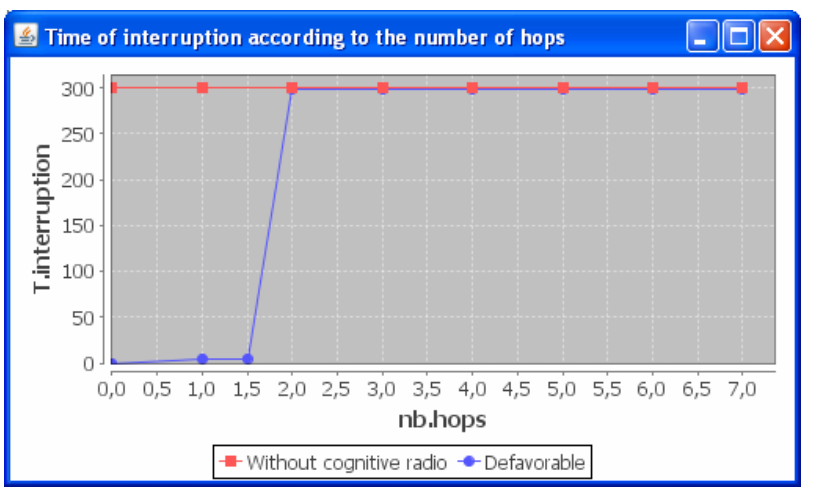

Figure 7. Comparison between the defavorable scenario and the case without cognitive radio

\section{4) Results interpretation}

Modeled graphs above represent the downtime depending on the number of hops performed. We note that whatever the number of hops, the case with the $\mathrm{CR}$ is much better than that without CR. According to the first graph, of course we lost 5 seconds to connect to the new band but we see that the CR has saved us 295 s which is the time without interruption.

For the second graph, we performed three hops, which means that the downtime is $5 \mathrm{~s}$ x 3 hops: 15s. Despite this, the case with CR is always better. On the third graph, a single hop was made but the connection was interrupted by the primary user at the beginning, so we took advantage of the CR for a few seconds.

Result whatever the number of hops performed, the use of cognitive radio is always more efficient.

\section{CONCLUSION}

We presented in this paper a new approach that uses cognitive radio to improve video conferencing application quality for a CRMT. The usefulness of cognitive radio is a hypothesis that has been proved based on the required time for a connection to a new frequency band, and this, whatever of the number of frequency bands that a terminal used to remedy a failed connection. In our future work, we will seek to reduce the impact of mobility on cognitive radio communications by building predictive models of mobility by referring to previous work such as [9] [10] [11] [12] [13].

\section{REFERENCES}

[1] J. Mitola, Cognitive radio - model-based competence for software radios, Licentiate Thesis, KTH, Stockholm (September 1999).

[2] J. Neel, "Analysis and Design of Cognitive Radio Networks and Distributed Radio Resource Management Algorithms", Faculty of the Virginia Polytechnic Institute and State University, September 2006.

[3] J-P. Vasseur, M. Pickavet, and P. Demeester, "Network Recovery: Protection and Restoration of Optical", SONET-SDH, IP, and MPLS, Elsevier, Ed. Morgan Kauffman, 2004.

[4] A. P. Snow, U. Varshney, and A. D. Malloy, "Reliability and survivability of wireless and mobile networks," Computer, vol. 33, no. 7, Jul. 2000.

[5] D. Tipper, T. Dahlberg, H. Shin, and C. Charnsripinyo, "Providing fault tolerance in wireless access networks," IEEE Commun. Mag., vol. 40 no. 1, Jan. 2002.

[6] D. Tse and P. Viswanath, "Fundamentals of Wireless Communications". Cambridge University Press, 2005.

[7] S. Busanelli, M. Martalõ, G. Ferrari, and G. Spigoni, "Vertical Handover between WiFi and UMTS Networks: Experimental Performance Analysis", International Journal of Energy, Information and Communications Vol. 2, Issue 1, February 2011.

[8] Z. Daia, R. Fracchiaa, J. Gosteaub, P. Pellatia, G. Viviera, "Vertical handover criteria and algorithm in IEEE 802.11 and 802.16 hybrid networks", Laboratoire de Motorola Paris.

[9] N. Samaan, B. Benmammar, F. Krief, A. Karmouch. "Prediction-based Advanced Resource Reservation in a Mobile Environment". 18th IEEE Annual Canadian Conference on Electrical and Computer Engineering, CCECE05, May 1-4, 2005, Saskatoon Inn, Saskatoon, Saskatchewan Canada.

[10] B. Benmammar and F. Krief. "MQoS NSLP: a mobility profile management based approach for advance resource reservation in a mobile environment". Proceedings of the 7th IFIP IEEE International Conference on Mobile and Wireless Communications Networks (MWCN 2005). Marrakech, Morocco. September 19-21, 2005.

[11] A. Amraoui, W. Baghli et B. Benmammar, "Amélioration de la fiabilité $\mathrm{du}$ lien sans fil pour un terminal radio cognitive mobile", 12 ème Journées Doctorales en Informatique et Réseau (JDIR'11), Belfort, France, Pages : 1-6, 2011.

[12] B. Benmammar, A. Amraoui and W. Baghli, "Performance improvement of wireless link reliability in the context of cognitive radio". IJCSNS International Journal of Computer Science and Network Security, Vol.12, No.1, Pages: 15-22, 2012.

[13] A. Amraoui and al, (2012) "Toward cognitive radio resource management based on multi-agent systems for improvement of real-time application performance", 5th IFIP International Conference on New Technologies, Mobility and Security (NTMS 2012). Istanbul, Turkey, May 7th-10th. 